\title{
10+2 Agenda for Public Health in Nepal
}

\author{
Gautam KC \\ 'Former Assistant Secretary-General of the United Nations and Deputy Executive Director of UNICEF
}

\section{ABSTRACT}

Public health has come a long way in Nepal, but there is still a long way to go. Over the past years some remarkable achievements have been made in millennium development goals, such as reduction of child mortality, maternal mortality and fertility. However, there still exist wide gaps in health coverage among different ethnic groups, geographic regions and gender. In this context, a 10+2 agenda is recommended for scaling-up essential health care in Nepal. These focus on equity, tackling malnutrition, prioritizing non-communicable diseases, preventing accidents, injuries and disabilities, promoting environmental health, harnessing the power of education and communication for behavior change, strengthening health systems, fostering public-private partnership, capitalizing on international health partnerships, as well as institutionalizing a culture of non-violence, and consolidating genuine democracy.

Key Words: 10+2 agenda, Nepal, public health

\section{INTRODUCTION}

Public health is defined as "the science and art of preventing disease, prolonging life and promoting health through the organized efforts and informed choices of society, organizations and individuals." ${ }^{1}$ There are two distinct characteristics of public health: first, it deals with population-level rather than individual-level health issues, and second, it emphasizes preventive rather than curative aspects of health.
How are we doing in terms of public health in Nepal? Lately, there has been much debate about the huge remaining challenges in public health, but the achievements made so far should not be under-valued.

\section{Progress in Public Health in Nepal}

Nepal has made some significant progress, and it is on track to achieve - and even exceed - quite a few of the

Correspondence:

Mr. Kul Chandra Gautam

Former Assistant Secretary-General of the United Nations

Former Deputy Executive Director of UNICEF

Kathmandu, Nepal.

Email: kulgautam@hotmail.com 
Millennium Development Goals - such as reduction of child mortality, maternal mortality and fertility, access to drinking water supply and basic education. ${ }^{2}$ Under five mortality, which is a very sensitive indicator of broader socio-economic development, has been reduced in Nepal by $80 \%$ from 250 to 50 per 1000 live births in the past half-century. What is especially remarkable is that even during the last decade, when we had a terrible civil war, with thousands of civilian deaths each year, destruction of infrastructure and interruption of many basic services in rural areas, both child deaths and child birth rates, and even maternal mortality rates, continued to decline sharply.

Some of the greatest success stories in preventing deaths and disabilities in our life time in Nepal have been eradication of smallpox, virtual eradication of polio, virtual elimination of leprosy, iodine deficiency disorders (IDD) and Vitamin A deficiency, and significant reduction in iron deficiency anemia affecting large numbers of women and children. Children of Nepal today are healthier, more educated and more knowledgeable about the world than in any previous generation. And there has also been much progress in women's health, education, and their overall status in society, which is so vital for national development.

\section{Disparities and Inequality}

Despite the marked improvements in public health, challenges still remain. Perhaps the biggest challenge is to narrow the gap in coverage of essential health services among people of different caste and ethnic groups, different geographic regions, between male and female, and between the rich and the poor. In light of this mixed picture of relatively good progress in expanding essential health services, but with major problems of equity, what follows is a $10+2$ agenda for uplifting the public health sector in the coming decade:

\section{Scaling-up Essential Health Care:}

We must redouble our efforts to scale-up all of our essential health services - substantially increasing the number of trained health workers, ensuring that there is no shortage of essential medicines, upgrading health facilities, and even offering conditional cash grants for vulnerable populations. Nepal's new National Health Systems Plan (NHSP-II) outlines in considerable detail how further progress can be made to reduce maternal and newborn deaths, to control communicable diseases, to promote nutrition and food security, to deal with new, neglected, and reemerging diseases, and to find affordable ways of responding to non-communicable diseases. What we need now is to implement this plan diligently with strong partnerships, enhanced human resources, essential supplies, sufficient funds and reliable monitoring.

\section{Focus on Equity:}

Some significant gains have been made in the last decade in reducing inequalities in access to and utilization of family planning and child health services between different castes and ethnic groups, as well as between poor and wealthier citizens of Nepal. But some disparities persist. The new NHSP-II contains specific objectives to reduce cultural and economic barriers to accessing health care, services by the poor, Dalits, Janjatis, Muslims and deprived Madhesi communities. If we implement NHSPII faithfully the health sector can be in the forefront of fulfilling our dream of building a New Nepal of equity and social justice.

\section{Tackle Malnutrition:}

A key strategy to improve nutrition is to ensure household food security. But beyond food, control of infections and good caring practices are equally important. Improvement in women's nutrition and health before and during pregnancy, timely and exclusive breastfeeding, quality complementary feeding, provision of vitamins and minerals through fortified foods and supplements, and communitybased treatment of severe acute malnutrition ought to be priority interventions. Investing in nutrition and early child development can unleash a virtuous cycle of human development. So tackling malnutrition should be considered a key poverty reduction strategy.

\section{Prioritize Non-Communicable Diseases (NCD):}

Nepal is now going through an "epidemiological transition" with non-communicable diseases accounting for more than $44 \%$ of deaths and $80 \%$ of outpatient contacts . The risk factors for many of these diseases are environmental and lifestyle-related choices such as drug, alcohol and tobacco use, diet, lack of exercise or stress management. The main response to the challenge of NCDs is likely to be behaviour change and adoption of healthy life-styles. Prevention, early detection and control of hypertension and diabetes alone could greatly reduce the burden of most NCDs. Mental health problems are also grossly under-recognized but of growing concern in Nepal. The Government is slowly introducing a mental health component in our national health and social welfare programmes but the efforts are not sufficient.

\section{Prevent Accidents, Injuries and Disabilities:}

Accidents and injuries have become increasingly prominent, now accounting for $11 \%$ of total deaths, and the leading cause of disabilities. ${ }^{5}$ Road traffic accidents have grown to alarming proportions. The legacy of 10 years of civil war has led to increasing incidence of violence to resolve not just political disputes but all kinds of local and 
community-based conflicts. In response to the rising concern regarding accidents and injuries, NHSP-II aims to expand measures including safer driving, wearing of seatbelts and helmets, and improving the capacity to handle injuries from road traffic accidents. Further prevention, treatment and rehabilitation of people with disabilities merit increased priority commensurate with the magnitude of the problem.

\section{Promote Environmental Health:}

Ensuring universal access to safe drinking water, sanitation and hygiene ought to be our urgent national priority. We must invest in clean energy for cooking, heating and other chores in our households. To protect the health of urban dwellers we need to pursue a deliberately ecofriendly urban development policy. In response to the impact of global warming and climate change in public health, many policy instruments must be used, including generous tax incentives and even subsidies for vehicles and machineries that use non-polluting energy sources which minimize carbon emission and greenhouse gases. We must strive to build a carbon-neutral Nepal for our children and future generations.

\section{Harness the Power of Education and Communication for Behaviour Change:}

In the 1980s the former Director of the US Centers for Disease Control, Dr. Bill Foege, remarked that it would cost more than $\$ 10$ billion annually to add a single year to the life expectancy of an average American through medical interventions, but 11 years could be added to their life expectancy through four virtually cost-free actions: a) stop smoking, b) moderate alcohol consumption, c) change certain dietary habits, and d) do moderate amount of exercise regularly. ${ }^{6}$ To these one could add a few more behavioral changes, especially relevant in developing countries like Nepal, such as practicing exclusive breastfeeding, hand-washing, safe sex and following basic traffic rules. None of these require sophisticated medical technology, highly trained manpower or huge investments; what they require is behaviour change. Empowering parents with knowledge and skills, utilization of the media and media personalities and a strong school-based health education programme to influence behavior could do wonders to promote public health.

\section{Strengthen Health Systems:}

To back up the health-seeking efforts of people themselves, we must have a strong public health system in the country. Over recent decades Nepal has built up a work force of trained health professional and para-professionals, and developed a network of sub-health posts, health posts, primary health care centers, district hospitals and referral services. Currently, many of these health professionals and institutions perform sub-optimally, and it is our duty to strengthen our health systems to make them more effective. Further improvements will require a better functioning health system that is able to respond to emergencies $24 / 7$. There is also a critical need to strengthen district hospital services to respond to referral requests from peripheral health units as well as to cater to the increasing demands for basic curative care.

\section{Foster Public-Private Partnerships (PPP):}

Some 44 percent of total health expenditure in Nepal is public and 56 percent comes from private sources. ${ }^{7}$ The private health sector owns and operates two thirds of Nepal's hospital beds, and employs around 20,000 people. Thus it is clear that the private sector plays a very important role in the provision of specialized health care. There is considerable room for mutually beneficial partnerships between the private and public sector to secure more benefits for ordinary Nepalese. One area crying out for urgent action is to enact and enforce clearer norms and regulations, without the Government becoming involved in micro-managing these institutions. The not-for-profit sector offers some good examples of public-private partnerships such as Non-Government Organization (NGO) management of Government hospitals. We need to develop a clear policy framework for PPP, to regulate and encourage the private sector to expand services to underserved communities.

\section{Capitalize on International Health Partnership (IHP):}

Recognizing Nepal's needs, good performance, and potential for further progress, Nepal was invited to be a founding partner of the International Health Partnership, and signed the IHP Global Compact in London in 2007., At the heart of the International Health Partnership there is a mutual commitment to get better results by increasing support for national health strategies and plans in a wellcoordinated way. Some of the areas for improvement in IHP that need to be prioritized include better guidance by Ministry of Population and Health, better alignment of External Development Partners' (EDP) planning with the Nepal Government's budget cycle, reduction in transaction costs and greater reliance on the SWAP planning and monitoring processes, more joint missions, improved longer term indications of donor support and stronger commitment by the Government to ensure more rational staff deployment, and more vigilant control of corruption.

Under normal circumstances the above 10 action points should be enough to build the foundations for strong public health in Nepal. However, it is difficult to promote 
public health when the whole body politic of the country is sick and unhealthy. Hence we need:

\section{Institutionalize a Culture of Non-Violence:}

Today Nepal suffers from a new disease of epidemic proportion - it is called the "culture of violence". We are all familiar with the deplorable kidnapping of high-profile doctors and their family members, but the daily acts of threats, intimidation, and extortion affect all segments of Nepali society. Schools and hospitals are supposed to be "zones of peace", off-limit for violent and militant activities. But in Nepal they often become hubs of violent political activism. We must reject this cancer of violence as an acceptable means for achieving any worthy goals. Most importantly, we must inculcate in the minds and hearts of our children and youth the values of nonviolence and peaceful pursuit of all worthy goals.

\section{Consolidate Genuine Democracy:}

The World Health Organization (WHO) defines health as being "a state of complete physical, mental and social well-being and not merely the absence of disease or infirmity". Such well-being is only possible in a fullfledged democracy with a thriving economy in which people can live a long, healthy, productive and creative life. Democracy does not produce instant results, and in our impatience and frustration, let us not be tempted to look for other non-democratic short-cuts. Above all, let us guard against demagogues who tend to emphasize what divides us rather than what unites us as Nepalis. As the level of education and sophistication of our people grows, and as democracy takes deep roots, we can expect the people of Nepal to attain the state of health as envisaged in the WHO definition. Better health in turn will unleash a virtuous cycle of greater productivity and prosperity, and peace of mind that we all cherish.

\section{SUMMARY}

The $10+2$ agenda, if properly followed, could raise the quality of public health in Nepal and would reduce the wide gaps between rich and poor, different ethnic groups and geographic regions. Pursuing this agenda in the spirit of public-private partnership, would enable the entire citizenry to enjoy universal coverage of health and wellbeing.

\section{REFERENCES}

1. Winslow CEA. The Untilled Fields of Public Health. Science 1920;51:23-33.

2. UNDP. Meeting the millennium development goals in Nepal. [Online]. 2010 Mar [Cited 2010 Jun 12]. Available from:

3. UNICEF. Statistics Nepal. [Online]. 2010 Mar 2 [Cited 2010 Jun 12]. Available from:

4. WHO. Surveillance of major non-communicable diseases in the south-east asia region. New-Delhi: WHO; 2001. Available from: URL:http:/ / www.searo.who.int/LinkFiles / Reports_and_Publications_NCD-48.pdf

5. WHO. 10 facts on injuries and violence. [Updated 2008 Mar 12; cited 2008 Oct 25]. Available from:

6. Gautam KC. Lesson from Jim Grant's Vision for Public Health. Dhaka: James P. Grant School of Public Health BRAC
University; 2005. Available from: URL:http:// www.bracuniversity.net/I\&S/sph/publications/reports/m onograph/Monograph\%20Series\%20-1.pdf

7. WHO. Country health system profile Nepal. [Online]. 2007 Aug [Cited 2010 Jun 12]. Available from:

8. IHP. IHP+ Global Compact. London: IHP; 2007. Available from: URL:http:/ / www.internationalhealthpartnership. net/CMS_files/documents/ihp_global_compact_EN.pdf

9. IHP. International health partnership [Online]. [Cited 2010 Jun 10]. Available from: URL:http://www. internationalhealthpartnership.net/en/documents 